\title{
Diapause completion in the almond seed wasp, Eurytoma amygdali (Hymenoptera: Eurytomidae) following early low temperature treatment
}

\author{
JoHN T. MARGARITOPOULOS ${ }^{1}$ and MinOs E. TZANAKAKIS ${ }^{2 *}$ \\ ${ }^{1}$ Laboratory of Entomology and Agricultural Zoology, Department of Agriculture, Crop Production and Rural Environment, \\ University of Thessaly, Fytokou Street, 38446 Nea Ionia, Magnesia, Greece; e-mail: jmarg@uth.gr \\ ${ }^{2}$ Aristotle University of Thessaloniki, 54006 Thessaloniki, Greece
}

Key words. Diapause development, diapause termination, insect dormancy, low temperatures, almonds, almond seed wasp, Eurytomidae

\begin{abstract}
Fruit of two almond, Prunus amygdalus Linnaeus, cultivars (Retsou and Truoito) containing diapausing larvae of Eurytoma amygdali Enderlein, were collected in early August from coastal areas in northern Greece. Some larvae were removed from the fruit and maintained singly in open plastic vials and others left in the fruit until the end of the low-temperature period. They were kept at a low temperature of $10^{\circ} \mathrm{C}$ from the beginning, or after 8 weeks at $20^{\circ} \mathrm{C}$. The larvae were subsequently maintained at $20^{\circ} \mathrm{C}$ and whether they completed the two diapause stages was recorded for 60 more weeks. When the larvae in vials, were kept initially for 8 weeks at $20^{\circ} \mathrm{C}$, most of those from Retsou and all of those Truoito almonds completed the first stage of diapause. Of the larvae in the fruits, most of those in Truoito but less than $50 \%$ of those in Retsou almonds completed the first stage of diapause after 8 weeks at $20^{\circ} \mathrm{C}$. Larvae from different orchards and different almond cultivars differed in diapause intensity. When the larvae were kept at a low temperature of $10^{\circ} \mathrm{C}$ from the beginning for 4,8 or 16 weeks and then at $20^{\circ} \mathrm{C}$ they completed the second diapause stage synchronously, but the time of completion was delayed, and depended on the duration of the low temperature treatment. In several cases the time to diapause completion was bimodally distributed and the relative size of peak depended on the duration of the early exposure to low temperature.
\end{abstract}

\section{INTRODUCTION}

The almond seed wasp Eurytoma amygdali Enderlein (Hymenoptera: Eurytomidae) is a pest of almonds, Prunus amygdalus Linnaeus (Rosaceae), in a number of countries in southeastern Europe and the Middle East, as well as France, Armenia, Azerbaijan and Georgia (Zerova \& Fursov, 1991 and references therein). It is a univoltine species, with part of the population completing its life cycle in two years or, according to certain authors, in three or even four years because of a prolonged diapause. The egg is deposited within the almond seed. The larva feeds on the embryo, and upon completes its growth, sometime in mid-summer, it enters diapause within the usually intact seed integument. For references on the biology and seasonal development see Zerova \& Fursov (1991) and Tzanakakis et al. (1991). Plaut (1972) reported that in Israel, diapause terminates in January. He observed that early in diapause the larva has a dull grey colour and later becomes white. This conspicuous change in colour is caused by the larva defecating, which in Israel occurs mainly in November. The change of colour during diapause development gives a clear and useful distinction between the first, grey, and second, white, diapause stage in this insect. In the area of Thessaloniki in northern Greece, the first diapause stage is completed sometime between late September and late November and the second some time between late December and late January (Tzanakakis et al., 1991).
In the laboratory, over $50 \%$ of the larvae from trees of the Aristotle University of Thessaloniki Farm in northern Greece completed the first diapause stage within 8 to 12 weeks at $19^{\circ} \mathrm{C}$, but the second stage required considerably lower temperatures. Therefore, the two morphologically distinct diapause stages require different thermal optima for completion and/or termination, a moderate temperature for the first and a low temperature for the second (last) diapause stage (Tzanakakis et al., 1991). This was confirmed by Tzanakakis \& Veerman (1994), who also found that photoperiod did not affect diapause completion in the populations from coastal northern Greece.

In this study, in contrast to previous studies, the larvae were kept at the low temperature needed for the completion of the second diapause stage not only from the beginning of the second but also the beginning of the first diapause stage. Such an early exposure to low temperature is not experienced in nature by larvae in this area. The purpose of this was to see whether exposure to low temperature, at an "unnatural" time, would result in a subsequent synchronous completion of either diapause stage. A minority of the larvae in natural populations that undergo prolonged diapause and have a semivoltine life cycle, experience low temperatures in the first diapause stage, but not near its beginning. The insects first experience as larvae of the first diapause stage the warm summer and the mild autumn and subsequently the winter conditions. Before they experience winter conditions of

\footnotetext{
* Present address: R. Fereou 26, 15121 Pefki Attikis, Greece.
} 
the following year they have reached to the second, white, diapause stage. In this study the larvae removed from fruit and maintained in open vials from the beginning and those that remained inside the fruit until the end of the low-temperature treatment were compared. The purpose of this was to detect differences between the two conditions, and to exploit such knowledge in future experiments.

\section{MATERIAL AND METHODS}

Mummified almonds of two cultivars, each containing a fullygrown diapausing larva, were collected in early August from trees in two almond orchards of the farm of the Aristotle University of Thessaloniki. The farm is near the coast, at Micra, approximately $10 \mathrm{~km}$ south of the city of Thessaloniki in northern Greece. Almonds of the cultivar Retsou were collected from Orchards A and B, and of Truoito from Orchard B. At that time of the year, larvae in this locality have completed their growth and are at the beginning of diapause (Tzanakakis et al., 1991; Tzanakakis \& Veerman, 1994). After 4 days in open bags in a laboratory at $25^{\circ} \mathrm{C}$ and under natural daylight, the almonds were surface-treated momentarily with hot water to kill undesirable arthropods, and then dried at room temperature for 2 days. Subsequently, half the almonds were split open to remove the diapausing larvae, and half were split one day after low temperature treatment. The larvae taken out of the almonds were each placed in a cylindrical $15 \times 30 \mathrm{~mm}$ vial of semitransparent white plastic, of which the opened end was covered with tulle. The larvae were weighed, classified as "large' or "small", and approximately equal proportions of large and small larvae were included in each treatment. This was done to minimize differences in the sex ratio between treatments, following observations by the junior author that adult males were smaller than females. The treatments thus started on August 10, after the larvae had been in the laboratory for 8 days $\left(6\right.$ days at $25^{\circ} \mathrm{C}$ and 2 at room temperature). Larvae and almonds were subjected to the temperature treatments cited in the table and figures. In Experiments $2 \mathrm{a}$ and $2 \mathrm{~b}$ the larvae were subjected to a low temperature of $10^{\circ} \mathrm{C}$ and dark conditions at the very beginning of diapause. In Experiments $1 \mathrm{a}$ and $1 \mathrm{~b}$ the larvae experienced a period of 8 weeks at $20^{\circ} \mathrm{C}$ and $8 \mathrm{~L}: 16 \mathrm{D}$, at the end of the first or the beginning of the second diapause stage. Thus, Experiments $1 \mathrm{a}$ and $1 \mathrm{~b}$ can be considered as controls for Experiments $2 \mathrm{a}$ and $2 b$.

After each treatment, the larvae or the almonds were transferred to $20^{\circ} \mathrm{C}$ and $8 \mathrm{~L}: 16 \mathrm{D}$ for further diapause development and post-diapause morphogenesis. Tzanakakis \& Veerman (1994) showed that photoperiod had no effect on diapause completion and termination at temperatures close to those used in this study. Therefore, in the text that follows, the photoperiod is not cited. The larvae were examined every $1-2$ weeks. The change in the larvae from grey to white was the criterion for the completion of the first diapause stage, and pupation the criterion of the completion of the second diapause stage and of diapause itself. Although pupation, includes post-diapause morphogenesis and the possible effect of diapause-termination stimuli, it was used to indicate the "completion" of both diapause stages. Mortality during the experiments was generally low, not exceeding $5-10 \%$ in each treatment.

\section{Statistical analysis}

Dead insects were not included in the calculation of percentages of diapause completion. Thus, calculations were based on the 24-35 larvae per treatment that were alive at the end of the experiments. Comparisons of cumulative percentages of com- pletion of each diapause stage were made using Chi-square tests. When more than two percentages were compared and the Chi-square was significant, pairwise comparisons were conducted.

\section{RESULTS}

The results are presented in one table and figures. Table 1 contains the data recorded on only a few dates in order to give the reader an initial general picture and facilitate the subsequent study of the figures. However, it is the figures that give the detail and the full picture of the progress of completion of both diapause stages posttreatment up to the 60th week, and thus allow additional useful conclusions and discussion of the results.

\section{Completion of the first diapause stage}

Experiment 1a (larvae first exposed to $20^{\circ} \mathrm{C}$, in vials)

The larvae, each in a vial, were first exposed for 8 weeks to $20^{\circ} \mathrm{C}$ to allow all or most larvae to complete the first diapause stage, so that they were exposed to the low temperature at the beginning of the second diapause stage. A fairly high percentage $(67-88 \%)$ of the larvae from Retsou almonds from Orchard A, completed the first (grey) diapause stage by the end of the 8 th week at $20^{\circ} \mathrm{C}$ (Fig. 1). After subsequent exposure to $10^{\circ} \mathrm{C}$, the percentage that completed when exposed to $20^{\circ} \mathrm{C}$ further increased and finally reached $100 \%$. The fact that a further increase occurred during the second exposure to $20^{\circ} \mathrm{C}$, indicates that for Retsou larvae the initial 8 weeks at $20^{\circ} \mathrm{C}$ was insufficient for the completion of the first diapause stage of all the larvae. By contrast, in all three groups of larvae from Truoito almonds from Orchard B (Fig. 2), the cumulative percentage of completion of the first diapause stage reached $100 \%$ by the end of the initial 8 weeks at $20^{\circ} \mathrm{C}$ (week zero of figure). The total percentage completion, i.e. the percentage of all the larvae from the three treatments pooled together, differed significantly between Retsou and Truoito larvae: (84 vs. $\left.100 \%, X_{1}^{2}=23.4, P<0.001\right)$.

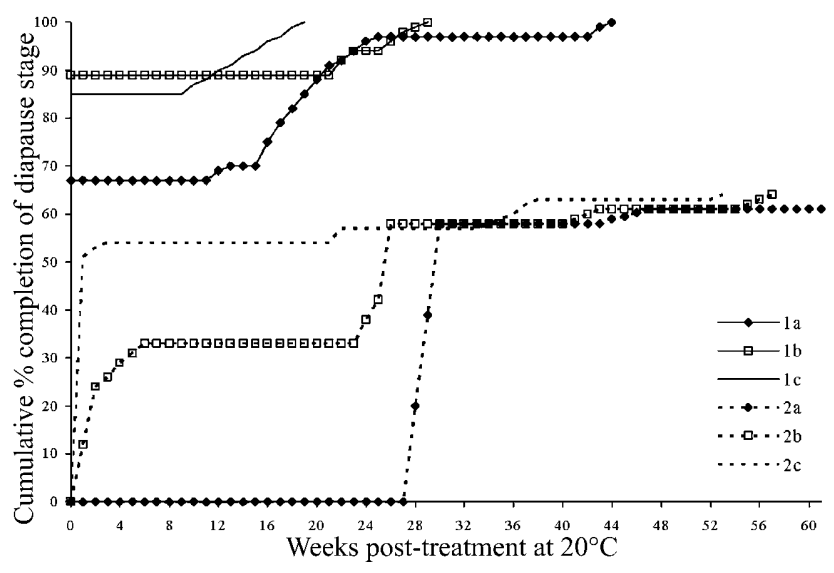

Fig. 1. Cumulative percentages completing the two diapause stages (first "1", and second " 2 "), at $20^{\circ} \mathrm{C}$, of larvae of Eurytoma amygdali from Retsou almonds from Orchard A collected in early August and kept in vials, first for 8 weeks at $20^{\circ} \mathrm{C}$, then for 4 (a), 8 (b), or 12 weeks (c) at $10^{\circ} \mathrm{C}$. Thirty five larvae per treatment. 
TABLE 1. Cumulative percentage completing the first and second diapause stages at $20^{\circ} \mathrm{C}$ of larvae of Eurytoma amygdali collected in early August from trees of two cultivars and exposed to $10^{\circ} \mathrm{C}$, in vials or inside fruit, for various periods.

\begin{tabular}{|c|c|c|c|c|c|c|c|c|c|c|c|}
\hline \multicolumn{2}{|c|}{ Numbers of weeks at } & \multicolumn{10}{|c|}{ Cumulative percentage completing in weeks $4-52$ post-treatment at $20^{\circ} \mathrm{C}$} \\
\hline \multirow{2}{*}{$20^{\circ} \mathrm{C}$} & \multirow{2}{*}{$10^{\circ} \mathrm{C}$} & \multicolumn{2}{|c|}{4} & \multicolumn{2}{|c|}{10} & \multicolumn{2}{|c|}{20} & \multicolumn{2}{|c|}{36} & \multicolumn{2}{|c|}{52} \\
\hline & & $1 \mathrm{st}$ & 2nd & $1 \mathrm{st}$ & 2nd & $1 \mathrm{st}$ & 2nd & $1 \mathrm{st}$ & 2nd & $1 \mathrm{st}$ & 2nd \\
\hline \multicolumn{12}{|c|}{ Larvae from Retsou trees from Orchard A, in vials } \\
\hline 8 & 4 & 67 & 0 & 67 & 0 & 88 & 0 & 97 & 58 & 100 & 62 \\
\hline 8 & 8 & 89 & 29 & 89 & 33 & 89 & 33 & 100 & 58 & & 62 \\
\hline 8 & 12 & 85 & 57 & 87 & 54 & 100 & 54 & & 60 & & 63 \\
\hline 0 & 4 & 4 & 0 & 53 & 0 & 70 & 0 & 87 & 18 & 96 & 47 \\
\hline 0 & 8 & 7 & 0 & 26 & 0 & 57 & 0 & 92 & 31 & 94 & 41 \\
\hline 0 & 16 & 9 & 0 & 18 & 0 & 89 & 0 & 94 & 19 & 94 & 37 \\
\hline \multicolumn{12}{|c|}{ Larvae from Retson trees from Orchard A, inside fruit } \\
\hline 8 & 4 & 49 & 0 & 49 & 5 & 100 & 5 & & 51 & & 51 \\
\hline 8 & 8 & 41 & 36 & 46 & 38 & 78 & 38 & 100 & 49 & & 53 \\
\hline 8 & 12 & 47 & 35 & 58 & 35 & 82 & 35 & 100 & 48 & & 50 \\
\hline 0 & 4 & 24 & 0 & 56 & 0 & 62 & 0 & 91 & 0 & 100 & 31 \\
\hline 0 & 8 & 3 & 0 & 29 & 0 & 41 & 0 & 85 & 8 & 94 & 12 \\
\hline 0 & 16 & 0 & 0 & 21 & 0 & 87 & 0 & 100 & 3 & & 23 \\
\hline \multicolumn{12}{|c|}{ Larvae from Truoito trees from Orchard B, in vials } \\
\hline 8 & 4 & 100 & 4 & & 4 & & 4 & & 88 & & 88 \\
\hline 8 & 8 & 100 & 63 & & 74 & & 74 & & 91 & & 91 \\
\hline 8 & 12 & 100 & 83 & & 83 & & 88 & & 88 & & 88 \\
\hline 0 & 4 & 91 & 0 & 91 & 0 & 91 & 0 & 100 & 16 & & 64 \\
\hline 0 & 8 & 50 & 0 & 58 & 0 & 75 & 0 & 83 & 63 & 100 & 71 \\
\hline 0 & 16 & 8 & 0 & 21 & 7 & 75 & 7 & 89 & 17 & 100 & 43 \\
\hline \multicolumn{12}{|c|}{ Larvae from Truoito trees from Orchard B, inside fruit } \\
\hline 8 & 4 & 100 & 4 & & 12 & & 12 & & 88 & & 88 \\
\hline 8 & 8 & 88 & 38 & 88 & 56 & 88 & 56 & 100 & 72 & & 80 \\
\hline 8 & 12 & 91 & 86 & 96 & 86 & 100 & 86 & & 90 & & 95 \\
\hline 0 & 4 & 60 & 0 & 71 & 0 & 71 & 0 & 97 & 4 & 97 & 50 \\
\hline 0 & 8 & 44 & 0 & 60 & 0 & 76 & 0 & 84 & 52 & 100 & 55 \\
\hline 0 & 16 & 0 & 0 & 65 & 0 & 80 & 0 & 93 & 15 & 95 & 50 \\
\hline
\end{tabular}

Experiment $1 \mathrm{~b}$ (larvae first exposed to $20^{\circ} \mathrm{C}$, inside fruits)

Of the Retsou larvae from Orchard A that remained inside fruit during the first 8 weeks at $20^{\circ} \mathrm{C}$ and the following 4,8 , or 12 weeks at $10^{\circ} \mathrm{C}$ (Fig. 3), the percentage that completed the first diapause stage during the initial 8 weeks at $20^{\circ} \mathrm{C}$ was much lower $(41-49 \%)$ than for the Retsou larvae removed from fruit and placed in vials from the start (Fig. 1). After the subsequent low temperature treatment, the percentage completion at $20^{\circ} \mathrm{C}$ gradually increased to $100 \%$. In contrast, for larvae inside Truoito fruit from Orchard B (Fig. 4), the percentage completion during the initial 8 weeks at $20^{\circ} \mathrm{C}$ was high. As for the larvae maintained in vials from the start, the total percentage completion of the first diapause stage was significantly lower for larvae from Retsou than from Truoito almonds (pooled data, 44 vs. 93\%, $X_{1}^{2}=44.9, P<0.001$ ).

For both cultivars the total percentage of larvae in fruit completed the first diapause stage by week 8 at $20^{\circ} \mathrm{C}$, prior to the low temperature treatment, was significantly lower than of larvae kept in vials from the start (Retsou:
44 vs. $80 \%, X_{1}^{2}=29.2, P<0.001$, Truoito: 93 vs. $100 \%$, $\left.X_{1}^{2}=5.2, P<0.02\right)$.

Experiment $2 \mathrm{a}$ (larvae first exposed to $10^{\circ} \mathrm{C}$, in vials)

Exposure was first to $10^{\circ} \mathrm{C}$ for 4,8 or 16 weeks, then continuously to $20^{\circ} \mathrm{C}$. As expected, because the temperature was too low none of the larvae completed the first diapause stage at $10^{\circ} \mathrm{C}$, irrespective of the duration of exposure (Figs 5-7). At the subsequent $20^{\circ} \mathrm{C}$, the percentage completion of the first diapause stage increased with time and almost reached $100 \%$. The early exposure to $10^{\circ} \mathrm{C}$ delayed the subsequent completion of the first diapause stage at $20^{\circ} \mathrm{C}$ of larvae from both almond cultivars, compared to when exposed to low temperature after they were initially kept for 8 weeks at $20^{\circ} \mathrm{C}$, but ultimately did not prevent a high percentage of the larvae from completing diapause (Table 1 and Figs 5-10). This was the case whether the larvae were in vials or in fruit until the end of the low temperature treatment. An exception are the larvae from Truoito almonds initially exposed 


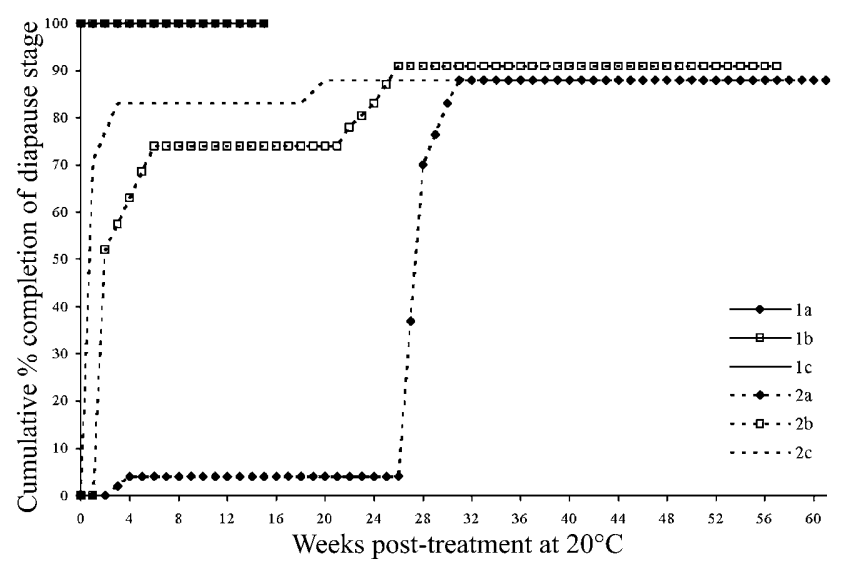

Fig. 2. Cumulative percentages completing the two diapause stages, at $20^{\circ} \mathrm{C}$, of larvae of Eurytoma amygdali from Truoito almonds from Orchard B collected in early August, and kept in vials at the temperatures given in Fig. 1. Twenty four larvae per treatment.

in vials to $10^{\circ} \mathrm{C}$ for only 4 weeks. For these larvae there was no delay in the completion of the first diapause stage (Fig. 7).

In general, some differences were observed in the rate of completion of the first diapause stage of larvae from the two cultivars. The percentage completion was higher in Truoito than Retsou larvae (Figs 5-7, treatments 1a, $1 b)$ in the subsequent 4 th week at $20^{\circ} \mathrm{C}$ after a 4 - and 8-week initial exposures to $10^{\circ} \mathrm{C}$ (4-week treatment: $X_{2}^{2}=$ 6.4, $P<0.04$; 8-week treatment: $\left.X_{2}^{2}=5.2, P<0.07\right)$. The opposite effect was observed after a 16-week initial exposure to $10^{\circ} \mathrm{C}$ (Figs $5-7$, treatment 1c) $\left(X_{2}^{2}=12.2, P<\right.$ $0.002)$, with the Retsou larvae from Orchard B showing the highest percentage completion. In addition, the Truoito larvae reached $50 \%$ completion earlier than Retsou larvae after the $4-$ and 8 -week at $-10^{\circ} \mathrm{C}$ treatments, while the opposite occurred after the 16-week treatment.

Experiment $2 \mathrm{~b}$ (larvae first exposed to $10^{\circ} \mathrm{C}$, inside fruit)

The larvae remained inside the almonds during their first 4,8 or 16 weeks at $10^{\circ} \mathrm{C}$. Subsequently the almonds were split open, and the larvae placed singly in vials at $20^{\circ} \mathrm{C}$. For larvae from the same almond cultivar the cumulative percentage completion/time curves were rather similar for larvae kept in vials from the start and those in fruits (compare Figs 5-7 with Figs 8-10). In week 8 at $20^{\circ} \mathrm{C}$ after low temperature exposure the only significant difference between exposed and in-fruit larvae were in the 8- and 16-week treatments of Retsou larvae from orchard B (Figs 6 and 9, 35 vs. 73\% and 57 vs. $21 \%, X_{1}^{2}=11.3, P<0.001$ and $X_{1}^{2}=10.2, P<0.001$, respectively) and 4-week treatment of Truoito larvae from the same orchard (Figs 7 and 10, 91 vs. $68 \%, X_{1}^{2}=4.6, P$ $<0.03$ ). Retsou larvae from Orchard B (Fig. 9), completed diapause earlier than those from Orchard A after all three periods of exposure to $10^{\circ} \mathrm{C}$. Truoito larvae from Orchard B (Fig. 10) responded similarly to the Retsou larvae from the same orchard (Fig. 9) up to $70 \%$ diapause

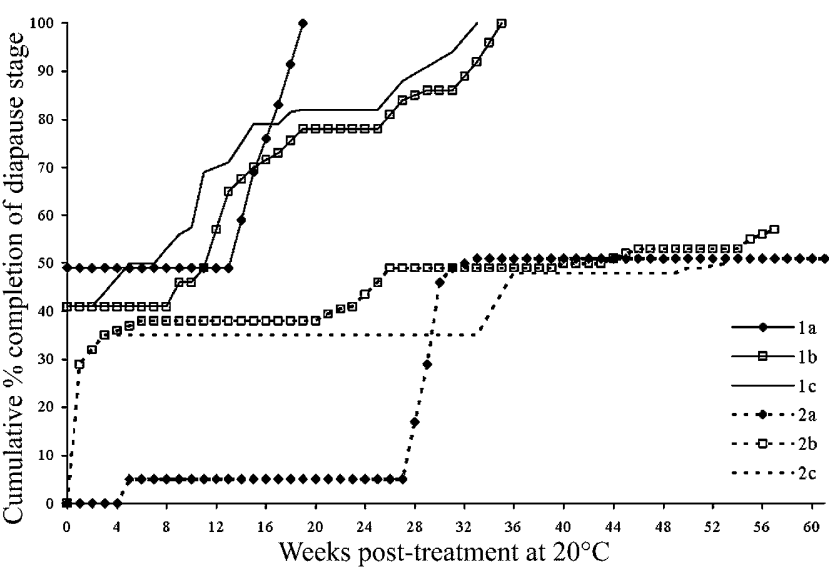

Fig. 3. Cumulative percentages completing the two diapause stages, at $20^{\circ} \mathrm{C}$, of larvae of Eurytoma amygdali from Retsou almonds from Orchard A, kept in almonds at the temperatures given in Fig. 1. Larvae kept in vials after the low temperature treatments. Thirty five larvae per treatment.

completion level. Above that level, Retsou larvae exposed to $10^{\circ} \mathrm{C}$ for 4 or 8 weeks, reached maximum values earlier than Truoito larvae. For the Retsou larvae from Orchard B (Fig. 9), the 50\% values and the maximum completing diapause occurred earlier than for the larvae from Orchard A (Fig. 8) as was observed for the larvae kept in vials from the start (Fig. 6 vs. 5).

\section{Completion of the second diapause stage}

"Completion" of the first diapause stage is marked by defecation, which is accompanied by the larva changing colour from grey to white. In addition, at the end of diapause development, "completion" of the second diapause stage includes a short period of post-diapause development of approximately 3 days at $20^{\circ} \mathrm{C}$ when the larvae pupated. This is a consequence of using pupation as a criterion of the end of the second stage.

Experiment 1a (larvae first exposed to $20^{\circ} \mathrm{C}$, in vials)

As seen in Fig. 1 larvae from almonds of the cultivar Retsou from Orchard A exposed to $10^{\circ} \mathrm{C}$ for 12 weeks (treatment $2 \mathrm{c}$ ), completed the second diapause stage early and synchronously within the first 1-3 weeks after transfer to $20^{\circ} \mathrm{C}$. Only a small percentage of these larvae completed diapause later. In larvae exposed to $10^{\circ} \mathrm{C}$ for 8 weeks (treatment 2b) diapause was completed in two periods 19 weeks apart, as if the population was composed of two genetically different populations with different diapause intensities. The completion of diapause in two separate periods has been observed in many other cases (see below). In larvae exposed to $10^{\circ} \mathrm{C}$ for only 4 weeks (treatment 2a) diapause termination was synchronous but much delayed. The percentage completing was virtually independent of the durations of the three low temperature treatments. By week 61, when the experiment ended, the percentage diapause completion did not exceed $64 \%$, with a substantial percentage of Retsou larvae remaining in diapause even after 12 weeks at $10^{\circ} \mathrm{C}$.

In larvae from the cultivar Truoito from Orchard B (Fig. 2), the time scale of the general picture was similar 


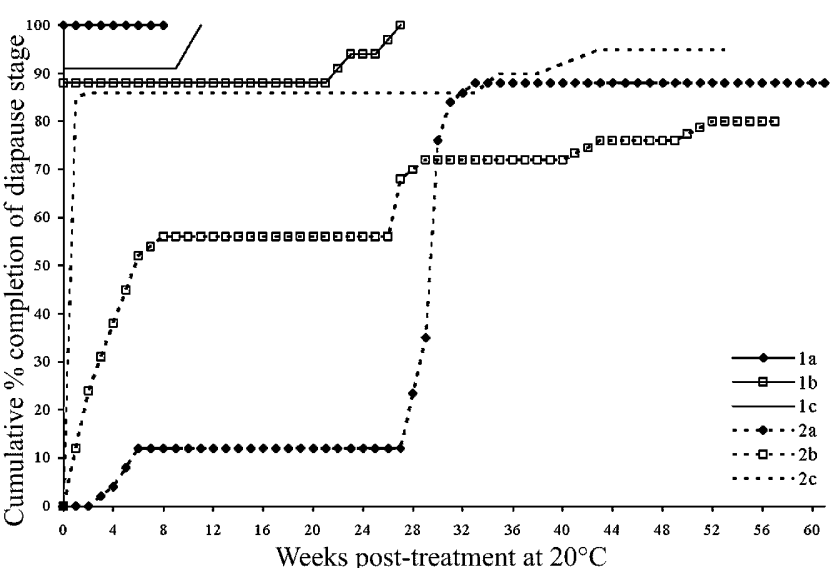

Fig. 4. Cumulative percentages completing the two diapause stages, at $20^{\circ} \mathrm{C}$, of larvae of Eurytoma amygdali from Truoito almonds from Orchard B collected in early August and kept in almonds at the temperatures given in Fig. 1. Larvae kept in vials after the low temperature treatments. Twenty four larvae per treatment.

to that of larvae from Retsou almonds from Orchard A, but the total percentages terminating diapause were significantly higher $\left(X_{1}^{2}=5.25, P<0.02, X_{1}^{2}=6.2, P<0.01\right.$ and $X_{1}^{2}=4.4, P<0.04$ for treatments $2 \mathrm{a}, 2 \mathrm{~b}, 2 \mathrm{c}$, respectively). Therefore, the larvae from Truoito almonds had a lower diapause intensity than those from Retsou almonds.

Experiment $1 \mathrm{~b}$ (larvae first exposed to $20^{\circ} \mathrm{C}$, inside fruits)

The ultimate percentage of larvae in Retsou almonds from Orchard A (Fig. 3) that completed diapause was roughly $10 \%$ less than that of larvae kept in vials (Fig. 1), although the differences were not significant (4-week treatment: $X_{1}^{2}=0.52, P<0.47$; 8 -week treatment: $X_{1}^{2}=$ $0.24, P<0.63$; 12-week treatment: $\left.X_{1}^{2}=0.93, P<0.33\right)$. The times to $50 \%$ completion were virtually identical.

The percentages of larvae in Truoito almonds from Orchard B (Fig. 4) that completed diapause and the time/percentage completion curves were similar to those of larvae from the same trees kept in vials from the start (Fig. 2). An exception are the larvae exposed to $10^{\circ} \mathrm{C}$ for 8 weeks (2b), which had a lower percentage completion during the first step of increase. The final percentages of Truoito larvae that completed diapause were higher than of Retsou larvae (Fig. 3 vs. Fig. 4), although the differences were not always significant (4-week treatment: $X_{1}^{2}$ $=8.3, P<0.004 ; 8$-week treatment: $X_{1}^{2}=3.1, P<0.08$; 12-week treatment: $\left.X_{3}^{2}=13.2, P<0.001\right)$.

Experiment $2 \mathrm{a}$ (larvae first exposed to $10^{\circ} \mathrm{C}$ in vials)

The completion of diapause was synchronous but delayed in the Retsou larvae from Orchard A, exposed to $10^{\circ} \mathrm{C}$ for 4 weeks (Fig. 5, treatment 2a). For the larvae exposed for 8 weeks (2b), completion was also delayed and the percentage that completed diapause synchronously was rather low (31\%) and then rose gradually after a pause of 10 weeks. Of the larvae exposed to $10^{\circ} \mathrm{C}$ for 16 weeks (2c), a small percentage completed diapause earlier than of those exposed to $10^{\circ} \mathrm{C}$ for shorter periods and then increased gradually over a period of 34 weeks.

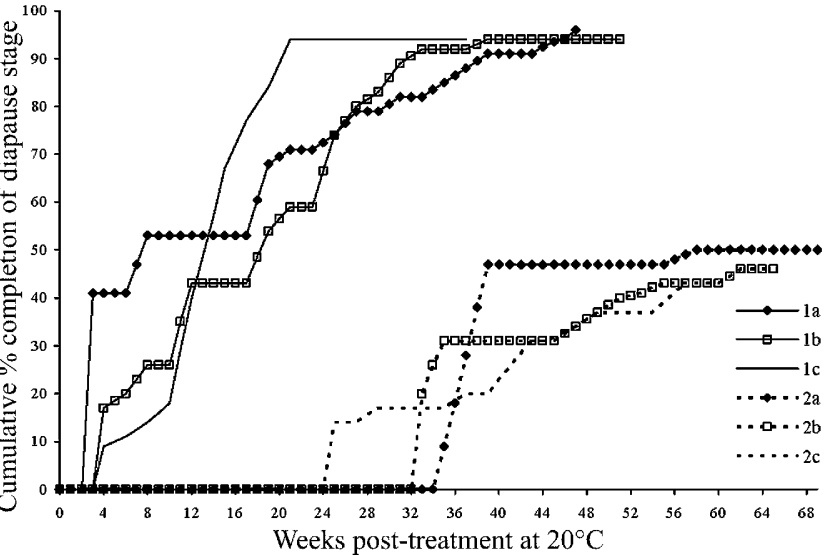

Fig. 5. Cumulative percentages completing the two diapause stages, at $20^{\circ} \mathrm{C}$, of larvae of Eurytoma amygdali from Retsou almonds from Orchard A collected in early August and kept in vials, first at $10^{\circ} \mathrm{C}$ for 4 (a), 8 (b) and 16 weeks (c). Thirty five larvae per treatment.

The final percentage that completed diapause did not differ substantially between the three different periods of exposure to $10^{\circ} \mathrm{C}$.

The percentages of the larvae from Retsou almonds from Orchard B (Fig. 6) that completed diapause after exposure to $10^{\circ} \mathrm{C}$ for 4 or 8 weeks $(2 \mathrm{a}, 2 \mathrm{~b})$, were higher than those of larvae from Orchard A. In the 16-week treatment completion started earlier, but remained much lower than in the 4- and 8-week treatments, although it did not differ significantly $\left(X_{2}^{2}=4.2, P<0.12\right)$. Diapause completion in two distinct periods was noticeable after all three exposures to $10^{\circ} \mathrm{C}$ and was also observed in Experiments $1 \mathrm{a}$ and $1 \mathrm{~b}$.

The time/cumulative percentage completion curves for larvae from Truoito almonds from Orchard B (Fig. 7) were similar to those for the Retsou larvae from the same orchard (Fig. 6) and the final percentages completioning diapause did not differ significantly for larvae from the two cultivars and orchards (4-week treatment: $X_{2}^{2}=0.8, P$ $<0.67$; 8-week treatment: $X_{2}^{2}=1.8, P<0.4$; 16-week treatment: $\left.X_{2}^{2}=0.9, P<0.6\right)$.

Experiment $2 \mathrm{~b}$ (larvae first exposed to $10^{\circ} \mathrm{C}$ inside fruit)

In this experiment the larvae were inside almonds during the low-temperature treatments. The percentages that completed diapause of the Retsou larvae from Orchard A (Fig. 8) were generally lower than for larvae from the same cultivar and orchard kept in vials from the start (Fig. 5), although the differences were not always significant (4-week treatment: $X_{1}^{2}=2.1, P<0.03$; 8-week treatment: $X_{1}^{2}=10.1, P<0.001 ; 16$-week treatment: $X_{1}^{2}=$ $0.98, P<0.32)$. The percentage completing diapause after 8 weeks at $10^{\circ} \mathrm{C}(2 \mathrm{~d})$ was unexpectedly lower than after 4 or 16 weeks. On the other hand, the same treatment of larvae from the same cultivar (Retsou) but from Orchard B (Fig. 9) gave a different picture, with a considerably higher percentage completing diapause after 8 weeks and very low values after 16 weeks at $10^{\circ} \mathrm{C}$. The shape of the time/cumulative percentage completion curves and the 


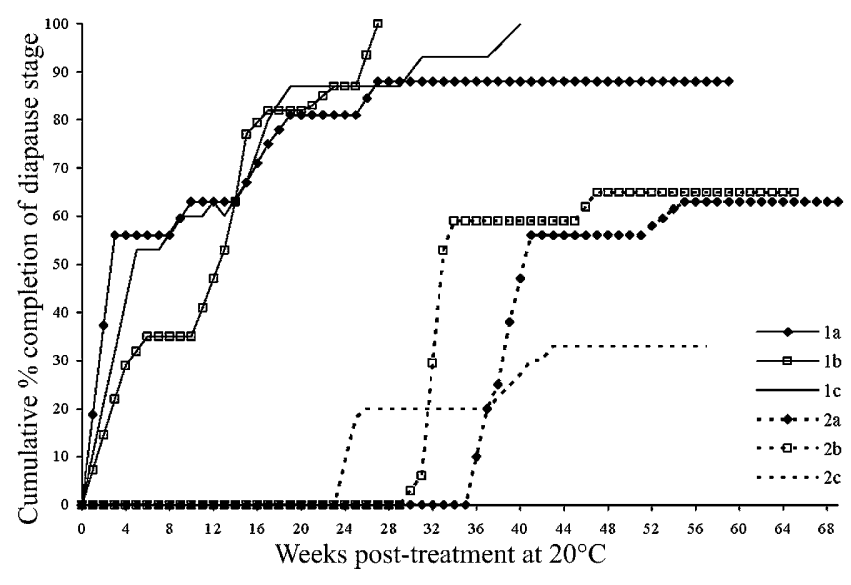

Fig. 6. Cumulative percentages completing the two diapause stages of larvae of Eurytoma amygdali from Retsou almonds from Orchard B collected in early August and kept in vials at the temperatures given in Fig. 5. Thirty five larvae per treatment.

final percentages completing diapause of the larvae from Truoito almonds from Orchard B (Fig. 10), were very close to those for larvae from the same cultivar kept in vials from the start (Fig. 7) (4-week treatment: 57 vs. $64 \%, X_{1}^{2}=0.1, \mathrm{P}<0.77 ; 8$-week treatment: 64 vs. $71 \%$, $X_{1}^{2}=0.38, P<0.54 ; 50$ vs. $\left.50 \%, X_{1}^{2}=0.01, \mathrm{P}<1.0\right)$, as were the times when diapause completion started and ended. Diapause completion in two distinct periods also occurred in this experiment.

Comparing the results obtained after the initial exposure to $10^{\circ} \mathrm{C}$ with those after the $10^{\circ} \mathrm{C}$ exposure after 8 weeks at $20^{\circ} \mathrm{C}$ (Figs $1-4$ vs. Figs 5, 7, 8 and 10), it appears that in most cases larvae from both cultivars (whether in vials or inside almonds) started to complete the second diapause stage earlier and in general reached higher final percentages of completion when exposed to $20^{\circ} \mathrm{C}$ prior to the low temperature treatment. The final total percentages of completion for Retsou larvae first exposed to $20^{\circ} \mathrm{C}$ before exposure to low temperature were for larvae kept in vials from the start and in fruit 63 and $53 \%$, respectively (Figs 1 and 3), and for larvae first exposed to $10^{\circ} \mathrm{C}, 46$ and $26 \%$ respectively (Figs 5 and 8 ) $\left(X_{1}^{2}=5.6, P<0.02\right.$ for larvae in vials; $X_{1}^{2}=15.7, P<$ 0.001 for larvae in fruit). The respective values for the Truoito larvae first exposed to $20^{\circ} \mathrm{C}$ were 89 and $88 \%$ (Figs 2 and 4) and 62 and 57\% for larvae first exposed to $10^{\circ} \mathrm{C}$ (Figs 7 and 10) $\left(X_{1}^{2}=14.8, P<0.001\right.$ for larvae in vials; $X_{1}^{2}=7.6, P<0.01$ for larvae in fruit).

\section{DISCUSSION}

More than one diapause stage with different photoperiod and/or temperature requirements for their completion have been recorded for a number of insects and mites (for references see Lees, 1955; Danilevskii, 1965; Beck, 1968, 1980; Braune, 1973; Tauber \& Tauber, 1976; Saunders, 1982; Danks, 1987, 1991; Hodek \& Hodková, 1988). In several insects that require low temperatures for normal diapause completion, high or mild temperatures must precede the low temperatures (Danks, 1987).

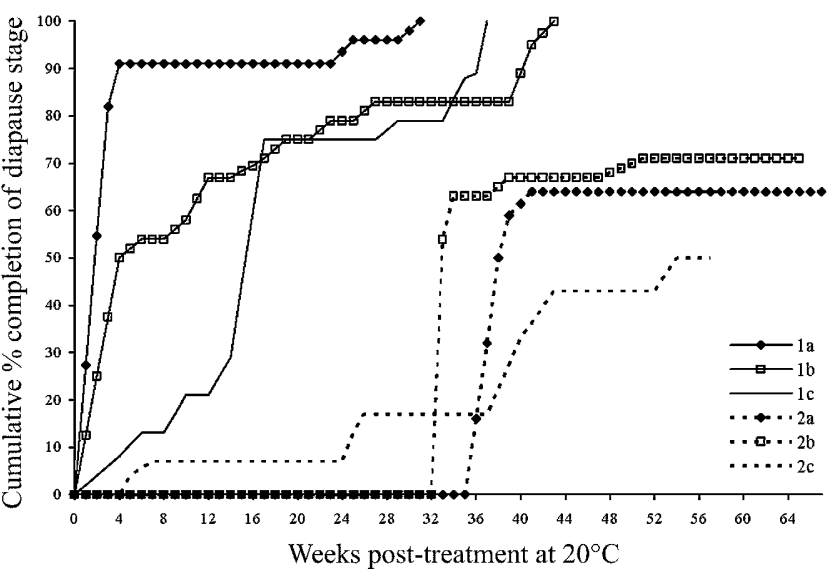

Fig. 7. Cumulative percentages completing the two diapause stages of larvae of Eurytoma amygdali from Truoito almonds from Orchard B collected in early August and kept in vials at the temperatures given in Fig. 5. Twenty four larvae per treatment.

The effect of temperature on the completion of the two diapause stages of $E$. amygdali were studied by Tzanakakis et al. (1991) and Tzanakakis \& Veerman (1994), using larvae from trees of the same two cultivars (Retsou and Truoito) and from the same locality in Greece as the present study. These authors showed that synchronous completing of the first diapause stage in most larvae needs exposure to mild temperatures such as $16-20^{\circ} \mathrm{C}$, whereas completing of the second stage needs exposure to low temperatures, such as $4-10^{\circ} \mathrm{C}$ or thermoperiods such as $16: 12^{\circ} \mathrm{C}$ or $16: 6^{\circ} \mathrm{C}$, for a number of weeks. For larvae from trees of the cultivars Retsou and Truoito collected in early August, 12 weeks of low temperature were needed for the second diapause stage to be completed, providing the first diapause stage was completed during the preceding 4-5 weeks of mild temperature. The Retsou larvae collected in late September, which were at a more advanced stage of diapause development than those collected in early August, only needed 8 weeks at $10^{\circ} \mathrm{C}$ (Tzanakakis \& Veerman, 1994). These findings accord with the temperature conditions prevailing in nature and the completion of diapause development. In autumn, when temperatures are mild the first stage is completed, and by mid-winter, after several weeks of low temperature in late November, December and January, the second stage is completed, and pupation occurs when the larvae experience higher mild temperatures, which allow morphogenesis. Under continuous $20^{\circ} \mathrm{C}$, without previous exposure to low temperatures, they did not complete the second stage of diapause synchronously, instead diapause completion extended over a long period and proportionally fewer completed diapause than those exposed to low temperatures.

\section{Low temperature applied after a period of $20^{\circ} \mathrm{C}$}

The completion of the second diapause stage by the Retsou and Truoito larvae after exposure to $10^{\circ} \mathrm{C}$ for 12 weeks accords with the findings of Tzanakakis et al. (1991) and Tzanakakis \& Veerman (1994). However, the 


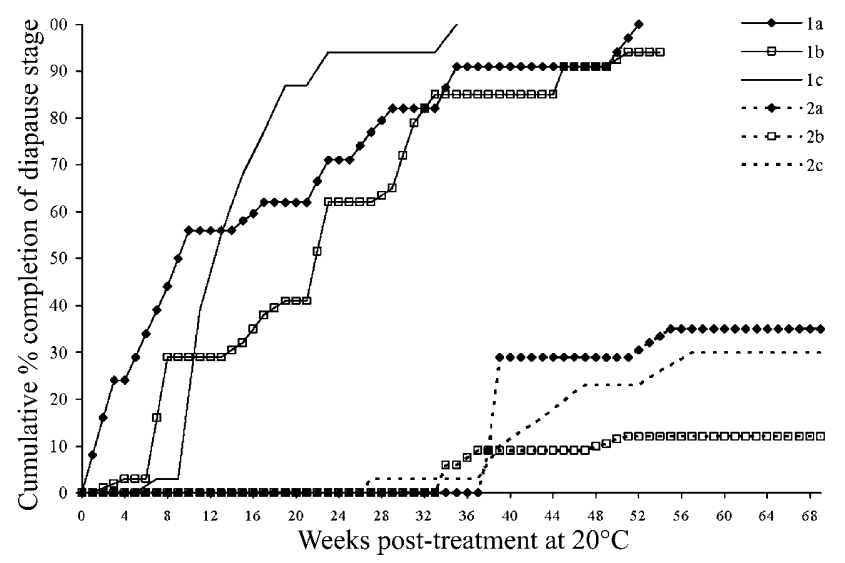

Fig. 8. Cumulative percentages completing the two diapause stages of larvae of Eurytoma amygdali from Retsou almonds from Orchard A collected in early August and kept in almonds at the temperatures given in Fig. 5. Larvae kept in vials after the low temperature treatments. Thirty five larvae per treatment.

present experiments revealed three new findings. The first is that an exposure to $10^{\circ} \mathrm{C}$ for 4 weeks is sufficient for a synchronous completion of diapause of most larvae. This occurs much later, starting at $20^{\circ} \mathrm{C}$ about 28 weeks later than after the longer exposures to $10^{\circ} \mathrm{C}$. The second finding is that the final (cumulative) percentage completing the first diapause stage was the same for all three durations of exposure to $10^{\circ} \mathrm{C}$. The third finding is that, especially after exposure to $10^{\circ} \mathrm{C}$ for 8 weeks, diapause completion occurred mainly in two distinct periods, as if the population was composed of two groups differing in diapause intensity. The percentage of larvae completing diapause in the first period differed among the larvae from the different tree cultivars, and whether they were inside fruit or in vials when exposed to low-temperatures. After 4- or 12-week exposures to low temperature, the bimodal distribution of diapause completion was less clear. The reason for this is unknown and certainly deserves further study.

Our species shares with many other temperate climate insects, which have an autumnal-hibernal diapause, the need to experience a minimum exposure to low temperature for synchronous diapause completion and early postdiapause morphogenesis when temperature increases. However, very few if any other species of insects in which temperature plays a major role in diapause completion respond similarly to E. amygdali. Among the closest, with respect to voltinism, feeding habits, diapausing stage and phenology are two other species of seed wasps. One is Megastigmus spermotrophus Wachtl (Hymenoptera: Chalcidoidea), which infests the seeds of Douglas fir, Pseudotsuga menziesii (Mirbel), in Scotland. It is also univoltine and the fully-grown larvae undergo an autumnal-hibernal diapause. Hussey (1955) collected infested seeds in October, placed them at $3.3^{\circ} \mathrm{C}$ in the dark, and at intervals removed some of the seed and kept it at a higher temperature. He found that, the longer the exposure to the low temperature the shorter the time to adult emergence, and the fewer individuals that remained

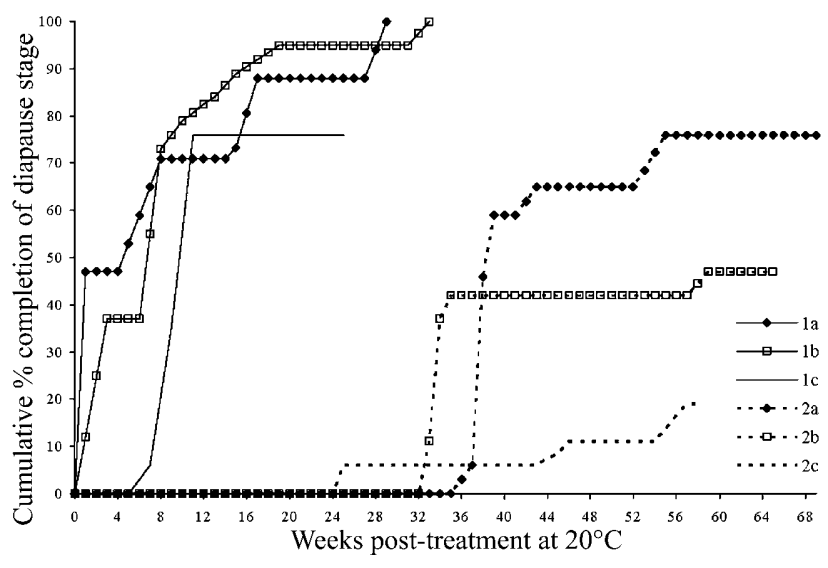

Fig. 9. Cumulative percentages completing the two diapause stages of larvae of Eurytoma amygdali from Retsou almonds from Orchard B collected in early August and kept in almonds at the temperatures given in Fig. 5. Larvae kept in vials after the low temperature treatments. Thirty five larvae per treatment.

in prolonged diapause. The other seed wasp species is Eurytoma plotnikovi Nikol'skaya (Hymenoptera: Eurytomidae). It is univoltine, infests the seeds of plants of the genus Pistacia, and in coastal northern Greece, undergoes an aestival-autumnal-hibernal-vernal diapause, which ends in mid-spring (Haralambidis \& Tzanakakis, 2000). This wasp has at least two diapause stages or phases. In the laboratory, larvae collected in early August completed the first stage more rapidly under a short-day and low temperature conditions, and the second stage more rapidly under a long-day and high $\left(26^{\circ} \mathrm{C}\right)$ to mildly high $\left(19^{\circ} \mathrm{C}\right)$ temperature conditions (Tzanakakis et al., 1992).

Among other species, Anomala cuprea Hope (Coleoptera: Scarabaeidae) studied by Fujiyama \& Takahashi (1973, from Fujiyama, 1983) enters diapause in autumn as a fully-grown larva. These authors found that the time to diapause completion at $25^{\circ} \mathrm{C}$, as judged from prepupation, decreased with increase in the initial exposure of the diapause larvae to $10^{\circ} \mathrm{C}$. Exposure to $10^{\circ} \mathrm{C}$ for 50 days resulted in a much earlier and more synchronous completion than exposure for 25 days, while no chilling resulted in an even later completion. That is most insects, including E. amygdali, require chilling for subsequent synchronous diapause completion. In Hyalophora cecropia (L.) (Lepidoptera: Saturniidae), a major part of the population needs low temperatures for the first phase of pupal diapause and high temperatures for the second phase (Waldbauer \& Sternburg, 1986). The two phases can be distinguished morphologically. This is the reverse of what happens in E. amygdali. Many more examples of insects and mites in which chilling favours synchronous diapause completion are given in the books and reviews cited at the beginning of this section.

Tauber \& Tauber (1976) state that one common factor in species that have low temperature optima for diapause development during their autumnal-hibernal diapause, is that warm conditions during late summer and early autumn ensure diapause maintenance. Warm conditions during these periods, to a lesser or greater degree, slow 


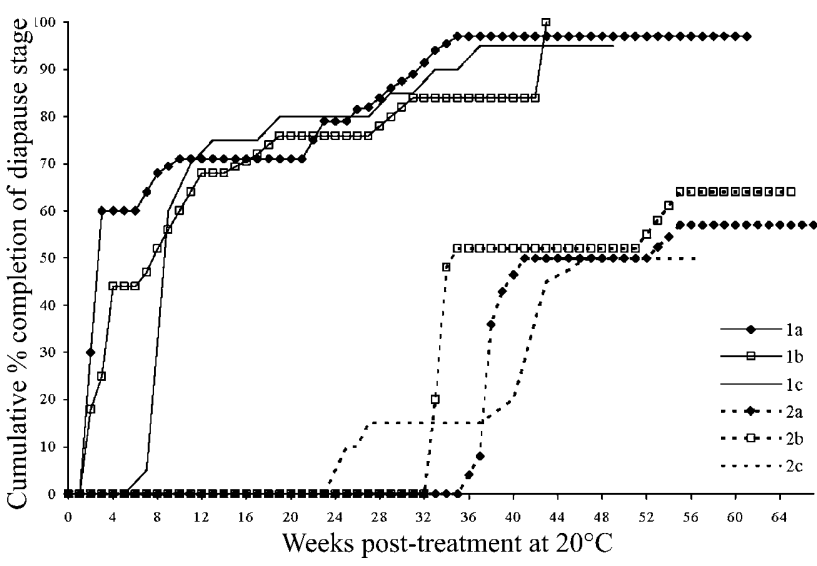

Fig. 10. Cumulative percentages completing the two diapause stages of larvae of Eurytoma amygdali from Truoito almonds from Orchard B collected in early August and kept in almonds at the temperatures given in Fig. 5. Larvae kept in vials after the low temperature treatments. Twenty four larvae per treatment.

and under some circumstances reverse the rate of diapause development. Thus diapause is maintained until autumn-winter temperatures drop below the threshold for growth. In E. amygdali the warm conditions in summer ensure diapause maintenance. However, in early to midautumn diapause development of the first stage proceeds at temperatures above the threshold for growth and in late autumn, and winter, during the second stage, diapause development proceeds at temperatures below the threshold for morphogenesis.

Hodek \& Hodková (1988) point out that, in addition to chilling, certain species from the temperate zone, which experience very cold winters, have high temperature optima for development of hibernal diapause. The larvae of E. amygdali were not exposed to high temperatures for long enough and in a variety of temperature levels and combinations to determine whether the species responds similarly.

\section{Low temperature applied first}

In nature, as a rule, the univoltine diapausing larvae of E. amygdali do not experience low temperatures of $10^{\circ} \mathrm{C}$ during the first diapause stage. An exception are the larvae in prolonged diapause, which in nature complete their life cycle in two and possibly more years. These larvae spend the first winter in the first diapause stage. Exposing the larvae first to a low temperature and then a mild temperature of $20^{\circ} \mathrm{C}$, was intentionally "unnatural". Tzanakakis \& Veerman (1994) also exposed larvae to a low temperature of $10^{\circ} \mathrm{C}$ at the beginning of the first diapause stage, but for longer (20 weeks), which resulted in no (Retsou larvae) or very low completion $(1.5 \%$ of Truoito larvae) of the first and the second diapause stages within the subsequent 16 weeks at $19^{\circ} \mathrm{C}$. This gave the impression that if larvae are exposed to a very long period of low temperature early in their first diapause stage they become refractory to change when subsequently maintained at the favourable temperature of $19^{\circ} \mathrm{C}$. In the present experiments, where the larvae were exposed to $10^{\circ} \mathrm{C}$ for shorter periods at or near the beginning of the first diapause stage, both Truoito and Retsou larvae did not become refractory to further change. The larvae regardless of the period for which they were exposed to low temperature completed the first and most also the second diapause stage. The latter suggests the delayed effect of low temperature, which is needed for the completion of the second diapause stage, is expressed later under the higher temperature of $20^{\circ} \mathrm{C}$. It is worth noticing, however, that an early exposure to $10^{\circ} \mathrm{C}$ was less beneficial, since in most cases it delayed the completion of the first diapause stage and resulted in less synchronous and delayed completion of the second diapause stage compared to when larvae were so exposed after an 8-week period at $20^{\circ} \mathrm{C}$.

Danks (1987) points out that, in several insects that require low temperatures for normal diapause completion, high or mild temperatures must precede the low ones. This applies also to E. amygdali, based on previous work (Tzanakakis et al., 1991; Tzanakakis \& Veerman, 1994) and also on the results of Experiments $1 \mathrm{a}$ and $1 \mathrm{~b}$ presented here. In addition, the results of Experiments $2 \mathrm{a}$ and $2 \mathrm{~b}$ show that a substantial but not a high percentage of the larvae failed to complete diapause synchronously, even if exposed to the low temperature first. Whether this completion is normal, is uncertain. In the present and most previous published work on larval diapause, the criterion of completion is pupation. Adult longevity and reproductive ability of the experimental insects was not compared with those of the respective natural population.

Among the species in which chilling was applied at the beginning of diapause is Calliphora vicina (RobineauDesvoidy) (Diptera: Calliphoridae). Vinogradova (1974) found that exposure of the diapausing larvae to $4^{\circ} \mathrm{C}$ for 1 to 3 months followed by $25^{\circ} \mathrm{C}$, was favourable for diapause completion, although at $25^{\circ} \mathrm{C}$ photoperiod also played a minor role. The eggs of Gryllulus commodus Walker (Orthoptera: Gryllidae) are most responsive to low temperature immediately after they are laid, that is, several days before they actually enter diapause (Browning, 1952, from Lees, 1955). Low temperature treatment is much less effective if delayed until the eggs have entered diapause. Among the species chilled during prediapause larval stages is $A$. cuprea. Of the chilled larvae (i.e., those exposed to $5^{\circ} \mathrm{C}$ for 55 days during their second or third instar) approximately $75 \%$ or more pre-pupated within the subsequent 10 days at $25^{\circ} \mathrm{C}$, while for unchilled larvae it was between 100 and 160 days (Fujiyama \& Takahashi, 1973)

It is not suggested that the temperature thresholds and optima for diapause development in E. amygdali change abruptly at the time the larvae change from grey to white. In other words it is not concluded that physiologically the requirements for completion change abruptly between the first and the second diapause stages; we only recorded different requirements of temperature in the two stages. The responses to early chilling may suggest that there is not a strict separation of requirements between the two stages. Whether diapause development proceeds gradu- 
ally, with temperature thresholds and optima changing gradually, or in steps, as suggested by Sawyer et al. (1993) for egg diapause in the gypsy moth, needs further investigation.

\section{Exposed vs. in-fruit larvae and differences between tree cultivars and orchards}

The results show that, with few exceptions, Retsou larvae in vials completed the first diapause stage earlier and the second stage in higher percentages than those inside fruit until the end of the $10^{\circ} \mathrm{C}$ treatment. For Truoito larvae, the differences were much smaller and involved the second stage of larvae exposed first to low temperature. These differences could not be attributed to the different photoperiods experienced by the larvae up to the end of the low temperature treatment inside fruit and in vials (dark and 8L : 16D, respectively), since Tzanakakis \& Veerman (1994) recorded no effect of photoperiod on diapause completion. Whether earlier illumination, aeration, humidity, or disturbance, as well as minor differences in the temperature fluctuations experienced by in- and out-of-fruit larvae are responsible for the observed differences remain to be determined.

There is some evidence that tree physiology may affect diapause intensity. The percentage of completion of the second diapause stage was lower for the Retsou larvae from orchard A than in those from orchard B, exposed first to low temperature for 4 or 8 weeks, whether in vials or inside fruit. Although the two orchards were only 500 $\mathrm{m}$ apart there were differences in cultural practices, including irrigation and fertilization. The orchards consist of trees of different ages, indicating possible derivation from different nurseries and genetic differences between the two populations of almond trees. Thus, from this study it is not possible to conclude anything about the effects of cultural practices on diapause intensity. Another point is that in all treatments Truoito larvae from orchard B showed a higher percentage of completion of the second diapause stage than Retsou larvae from orchard A, but there were no substantial differences between cultivars when both were from orchard B. It does not seems likely that these differences can be attributed to the almond cultivars, as other factors, such as discussed above, could also be involved. This indicates that further studies are needed to determine whether there are significant differences in diapause intensity between larvae from trees of different cultivars grown under similar conditions. Larvae from trees of the same genetic stock and age planted in the same locality but from orchards that differ in soil properties and/or cultural practices also need to be studied.

\section{Prolonged diapause}

Prolonged diapause is that which lasts more than one year under natural conditions (Tauber et al., 1986) or extends over more than one adverse season (Danks, 1987). Previous work (Tzanakakis et al., 1991) on larvae from coastal northern Greece feeding on almonds of the cultivars Truoito and Retsou, showed that in nature larvae that do not complete the first diapause stage before winter, remain in prolonged diapause. They complete the first stage after the following autumn and the second (last) stage the following winter. Tzanakakis et al. (1991) reported that the percentage of larvae in prolonged diapause in nature varied, depending on the year and almond cultivar, and for Retsou larvae it was approximately twice that for Truoito larvae. In the laboratory, using larvae from the same locality as in the present work, Tzanakakis \& Veerman (1994) recorded prolonged diapause in Retsou larvae of approximately 3 times that of Truoito larvae. The percentages in prolonged diapause in the present study in week 52 were $0-24 \%$ for Retsou and $0-5 \%$ for Truoito larvae. These percentages were for larvae kept for a long period at $20^{\circ} \mathrm{C}$, a condition that larvae do not experience in nature in northern Greece.

ACKNOWLEDGMENTS. Thanks are due to D.S. Koveos for critical comments on the manuscript and to E. Navrozidis for collecting the almonds from the trees.

\section{REFERENCES}

Beck S.D. 1968: Insect Photoperiodism. Academic Press, New York \& London, $288 \mathrm{pp}$.

BecK S.D. 1980: Insect Photoperiodism. 2nd ed. Academic Press, New York \& London, 387 pp.

BRAUNE H.J. 1973: The role of temperature in controlling obligatory diapause. In Wieser W. (ed.): Effects of Temperature on Ectothermic Organisms. Springer, Berlin, Heidelberg, New York, pp. 233-238.

BRowNING T.O. 1952: On the rate of completion of diapause development at constant temperatures in the eggs of Gryllulus commodus Walker. Aust. J. Sci. Res. (B, Biol. Sci.) 5: 344-353.

DANILEVSKII A.S. 1965: Photoperiodism and Seasonal Development of Insects. Oliver \& Boyd, Edinbourgh \& London (English translation), $283 \mathrm{pp}$.

Danks H.V. 1987: Insect Dormancy: An Ecological Perspective. Biological Survey of Canada (Terrestrial Arthropods), Monograph Series No. 1, Ottawa, $439 \mathrm{pp}$.

DANKS H.V. 1991: Life cycle pathways and the analysis of complex life cycles in insects. Can. Entomol. 123: 23-40.

FunIYAma S. 1983: The larval diapause of three scarabaeid beetles and its function in their life cycles. In Brown V.K. \& Hodek I. (eds): Diapause and Life Cycle Strategies in Insects. Dr. W. Junk, The Hague, Boston, London, pp. 55-66.

FuJiYAma S. \& TAKAHASHI F. 1973: Studies on the self-regulation of life cycle in Anomala cuprea Hope (Coleoptera: Scarabaeidae). 2. The effects of low temperature and photoperiod on the induction and termination of the larval diapause. Mem. Coll. Agric. Kyoto Univ. 104: 31-39.

Haralambidis C.G. \& TzanaKakis M.E. 2000: Time of diapause termination in the pistachio seed wasp Eurytoma plotnikovi (Hymenoptera: Eurytomidae) in northern Greece and under certain photoperiods and temperatures. Entomol. Hellen. 13: $43-50$.

Hodek I. \& Hodková M. 1988: Multiple role of temperature during insect diapause: a review. Entomol. Exp. Appl. 49: 153-165.

Hussey N.W. 1955: The life histories of Megastigmus spermotrophus Wachtl (Hymenoptera: Chalcidoidea) and its principal parasite, with descriptions of the developmental stages. Trans. R. Entomol. Soc. London 106: 133-151.

LeEs A.D. 1955: The Physiology of Diapause in Arthropods. Cambridge University Press, London, 151 pp. 
Plaut H.N. 1972: On the biology of the immature stages of the almond seed wasp, Eurytoma amygdali End. (Hym., Eurytomidae) in Israel. Bull. Entomol. Res. 61: 681-687.

SAunders D.S. 1982: Insect Clocks. 2nd. ed. Pergamon Press, Oxford, 409 pp.

Sawyer A.J., Tauber M.J., Tauber C.A. \& Ruberson J.R. 1993 Gypsy moth (Lepidoptera: Lymantriidae) egg development: a simulation analysis of laboratory and field data. Ecol. Model. 66: $121-155$.

TAUBER M.J. \& TAUBER C.A. 1976: Insect seasonality: diapause maintenance, termination, and post diapause development. Annu. Rev. Entomol. 21: 81-107.

Tauber M.J., Tauber C.A. \& Masaki S. 1986: Seasonal Adaptations of Insects. Oxford University Press, New York, Oxford, $411 \mathrm{pp}$.

Tzanakakis M.E. \& Veerman A. 1994: Effect of temperature on the termination of diapause in the univoltine almond seed wasp Eurytoma amygdali. Entomol. Exp. Appl. 70: 27-39.

TzanaKaKis M.E., KaraKassis E.J., TsaKlidis G., Karabina E.C., Argalavini I.C. \& Arabatzis G. 1991: Diapause termi- nation in the almond seed wasp, Eurytoma amygdali Enderlein (Hym., Eurytomidae), in northern Greece and under certain photoperiods and temperatures. J. Appl. Entomol. 111: 86-98.

Tzanakakis M.E., Veenendaal R.L. \& Veerman A. 1992: Effects of photoperiod and temperature on the termination of diapause in the univoltine seed wasp Eurytoma plotnikovi. Physiol. Entomol. 17: 176-182.

VinogRADOVA E.B. 1974: The pattern of reactivation of diapausing larvae in the blowfly, Calliphora vicina. J. Insect Physiol. 20: 2487-2496.

Waldbauer G.P. \& Sterniburg J.G. 1986: The bimodal emergence curve of adult Hyalophora cecropia: Conditions required for the initiation of development by second mode pupae. Entomol. Exp. Appl. 41: 315-317.

Zerova M.D. \& Fursov V.N. 1991: The palearctic species of Eurytoma (Hymenoptera: Eurytomidae) developing in stone fruits (Rosaceae: Prunoideae). Bull. Entomol. Res. 81: 209-219.

Received October 25, 2005; revised and accepted May 10, 2006 